\title{
Motor neuron diseases: Amyotrophic lateral sclerosis and spinal muscular atrophy
}

\author{
Ebru Sena Aslan ${ }^{1}$, Oytun Erbaş² \\ ${ }^{1}$ Demiroğlu Bilim University Faculty of Medicine, Istanbul, Turkey \\ ${ }^{2}$ Department of Physiology, Demiroğlu Bilim University Faculty of Medicine, Istanbul, Turkey
}

\begin{abstract}
Motor neurons are divided into upper motor neurons and lower motor neurons. Upper motor neurons transmit signals produced in the brain to the lower motor neurons. Lower motor neurons transmit these signals to the muscles of respective regions of the body to initiate motion. Injury to these motor neurons mainly result in motor neuron diseases, which may cause serious complications and death. This review discusses the definition, epidemiology, etiology, clinical symptoms, diagnosis, and treatment methods of the motor neuron diseases of amyotrophic lateral sclerosis and spinal muscular atrophy.

Keywords: Amyotrophic lateral sclerosis, lower motor neuron, spinal muscular atrophy, upper motor neuron.
\end{abstract}

Nerve cells that enable the flow of information between the central nervous system and peripheral nervous system by transmitting signals generated in the brain's motor cortex to the spinal cord, and from the spinal cord to skeletal muscles are called motor neurons. A motor neuron consists of a soma (cell body), axon (nerve fiber), and dendrites (terminal projections that receive signals).

Motor neurons are divided into upper motor neurons (first-order motor neurons) and lower motor neurons (second-order motor neurons). Cell bodies of upper motor neurons are found in the brain's motor cortex and transmit generated signals to the lower motor neurons in the brainstem and spinal cord anterior horn while continuously regulating these neurons. Although lower motor neurons with soma in the brainstem mostly innervate the head and neck muscles, those with soma in the spinal cord innervate the torso and limb muscles. Signals transmitted to the lower motor neurons are communicated to the respective muscles through the neuromuscular junction. Motor neuron diseases are characterized by the degeneration of first and second order motor neurons, and the term is generally used as an equivalent of amyotrophic lateral sclerosis (ALS), the most common of these diseases. ${ }^{[1]}$

While clinical signs such as hyperreflexia, clonus, hypertonia, extensor plantar reflex (Babinski sign), and muscle weakness are observed in upper motor neuron lesions, clinical signs of atrophy, muscle weakness, hyporeflexia, fasciculation, and hypotonia occur in lower motor neuron lesions. ${ }^{[1]}$ This review discusses the epidemiology, etiology, diagnosis, and treatment methods in the motor neuron diseases ALS and spinal muscular atrophy (SMA).

\section{AMYOTROPHIC LATERAL SCLEROSIS}

Amyotrophic lateral sclerosis is a progressive morbid disease that occurs as a result of degenerations of upper and lower motor neurons 
in the primary motor cortex, brainstem, and spinal cord. ${ }^{[1]}$ The first discovery of the disease is known to start with Aran Duchenne; however, it was first described by the French neurologist Dr. Jean-Martin Charcot, which is why the disease is also referred to as Charcot disease in many countries. ${ }^{[2]}$

Amyotrophic lateral sclerosis worldwide incidence is $4-8 / 100,000 .{ }^{[1]}$ Men have a higher incidence compared to women. ${ }^{[3]}$ Amyotrophic lateral sclerosis incidence increases with age. Age of onset varies between familial and sporadic cases. Mean onset is after 50 years of age in sporadic ALS, while familial ALS occurs about a decade earlier. ${ }^{[4-6]}$

The first gene discovered in ALS patients was the superoxide dismutase 1 (SOD1) gene located on chromosome 21.. ${ }^{[1,7]}$ Superoxide dismutase 1 protein produced by this gene exhibits antioxidant effect by breaking down superoxide radicals into hydrogen peroxide and molecular oxygen. Studies have suggested that mutation of this gene causes SOD1 protein to gain a toxic attribute. ${ }^{[1]}$ Superoxide dismutase 1 is responsible for $20 \%$ of familial cases. ${ }^{[8]}$ At the same time, studies on cell cultures have revealed that SOD1 overexpressing itself causes apoptosis in motor neurons. ${ }^{[9]}$

TAR-DNA-Binding Protein (TDP-43) was discovered after SOD1.10] This protein is synthesized in large numbers in all tissues ${ }^{[11]}$ and plays a role in RNA processing, transport, and splicing. ${ }^{[12]}$ TDP-43, normally found in the nucleus, accumulates as inclusions in the cytoplasm in pathological conditions. This is observed not only in ALS but also in frontotemporal dementia (FTD), which has pathophysiological mechanisms common to ALS. Autopsy studies on ALS patients conducted in the 1990s revealed ubiquitin positive inclusions in motor neurons. In 2006, it was concluded that TDP-43 was the main substance of low-solubility ubiquitin positive inclusions in ALS and FTD. ${ }^{[10]}$ Cytoplasmic aggregation of TDP-43 is not specific to ALS and FTD. Although it has also been observed in other neurodegenerative diseases, mutations of TDP-43 are specific to ALS and rarely in FTD. ${ }^{[1]}$

Fused in sarcoma (FUS) was discovered later on. ${ }^{[13,14]}$ These proteins play a role in RNA biology and DNA repair. ${ }^{[11,13]}$ They are normally found in the nucleus and are aggregated in the cytoplasm in ALS. ${ }^{[14]}$

Aside from these, there are many other causes of ALS. Genetic factors, apoptosis, heavy metals such as lead and mercury, glutamate excitotoxicity, trauma, oxidative stress, and viral infections may also play a role in ALS development. ${ }^{[15]}$ Early morbidity can occur 2-3 years after ALS onset due to respiratory failure and loss of mental and physical abilities. ${ }^{[16]}$ The life expectancy of ALS after diagnosis is 3-4 years but may vary between 1-20 years. ${ }^{[17-19]}$

\section{Clinical findings}

Symptoms of upper motor neuron and lower motor neuron involvement both observed in ALS. Upper and lower motor neuron findings differ. Although spasticity, clonus and some pathological reflexes are signs of upper motor neuron pathologies, atrophy, muscle weakness and fasciculations are signs of lower motor neuron pathologies. The predominance of these findings may vary from person to person, as well as a combination of both may be observed in limbs. ${ }^{[1]}$ At the same time, regions of initial symptoms may vary among patients. Spinal-onset ALS manifests as asymmetrical weakness that spreads to other regions of the body within a few months, also affecting respiratory muscles. ${ }^{[20-22]}$ Lower motor neuron symptoms in spinal-onset ALS include fasciculations, muscle atrophy, and hyporeflexia. Upper motor neuron symptoms include Babinski and Hoffman sign, hyperreflexia, and hypertonia. ${ }^{[22,23]}$

Bulbar-onset ALS is more common and account for about $20-30 \%$ of ALS patients. Since respiratory muscles are affected more quickly, these patients have generally shorter life expectancy compared to spinal-onset ALS patients. ${ }^{[22]}$ Lower motor neuron symptoms include atrophy, dysarthria, fasciculations in the tongue, and weakness in facial muscles. ${ }^{[22,24]}$ Upper motor neuron symptoms include slowing of tongue motions, slurred speech, as well as changes in speaking voice. ${ }^{[22,24,25]}$ Pseudobulbar effects may be present. These effects usually manifest as behaviors of uncontrolled crying and laughter. ${ }^{[22,25]}$ Frontotemporal dementia may also occur in ALS patients. Frontotemporal dementia is the second most common form of dementia following Alzheimer's disease. ${ }^{[22,26]}$ 


\section{Diagnosis}

Amyotrophic lateral sclerosis diagnosis requires thorough medical history accompanied by clinical findings. In addition, electrophysiological examinations also hold diagnostic significance. ${ }^{[27,28]}$ A number of laboratory methods may be used when necessary. In 1990, the El Escorial criteria (EEC) were developed to diagnose ALS. These criteria were later reviewed and the revised EEC was developed in 2000. ${ }^{28]}$

Later, the Awaji-Shima criteria increased the sensitivity of diagnosis in ALS. ${ }^{[29]}$ Awaji-Shima criteria sensitivity is $81.1 \%$ compared to EEC sensitivity of $62.2 \% .^{[30]}$

\section{Treatment}

Although there is no cure for this disease, medical and symptomatic therapies can improve the living standards of the patients. The food and drug administration-approved drug Riluzole is used in the medical treatment of the disease. Riluzole inhibits the presynaptic release of glutamic acid and reduces the neuronal damage caused by glutamic acid. In addition to riluzole, symptomatic therapy for weakness, insomnia, pseudobulbar involvement (uncontrolled episodes of laughter and crying), dysarthria (speech disorder), dysphagia (difficulty swallowing) and sialorrhea (failure to swallow saliva) during the course of the disease is also applied. ${ }^{[1]}$

\section{SPINAL MUSCULAR ATROPHY}

Spinal muscular atrophy is an autosomal recessive neuromuscular disease in which anterior horn cells in the spinal cord and motor nuclei in the brainstem undergo degeneration causing weakness and atrophy in muscles. As a result of failure to transmit signals from the muscle due to damage to the anterior horn cells, muscles undergo atrophy and weakness. ${ }^{[31,32]}$

\section{Etiology}

In 1995, the survival motor neuron (SMN) gene on chromosome 5 was identified as a cause of the disease. ${ }^{[3]}$ The SMN gene is expressed throughout body and produces the 294 amino acid SMN protein of $38 \mathrm{kDa} .^{[34]}$ This protein is found in the cytoplasm and nucleus. ${ }^{[5]}$ The SMN protein ensures axonal transport and integrity of motor neurons and is also effective in the formation of small nuclear ribonucleoproteins (snRNP) involved in mRNA splicing. ${ }^{[31,32]}$

This gene has two copies, the SMN1 (telomeric) and SMN2 (centromeric). ${ }^{[31]}$ They differ from each other by five nucleotides, but the most important difference is thymine instead of cytosine in exon 7 of SMN2. This does not alter the amino acid sequence, but exon 7 causes alternative splicing. ${ }^{[33,36]}$

While SMN1 produces full-length transcripts (SMNFL), 90\% of SMN2 produces transcripts that lack exon 7 (SMN $\Delta 7)$ and $10 \%$ produce fulllength transcripts (SMNFL). ${ }^{[3,36,37]}$ SMN protein stability affects oligomerization. ${ }^{[38]}$ SMN can self-assemble and oligomerize. ${ }^{[39,40]} \mathrm{SMN} \Delta 7$ will oligomerize less than SMNFL and its majority is produced as monomer. ${ }^{[39,40]}$ These monomers are unstable and will easily degrade, ${ }^{[38]}$ decreasing SMN protein levels in tissues. ${ }^{[32]}$

SMN1 is responsible for the pathogenesis of SMA. ${ }^{[31]}$ About $95 \%$ of patients have homozygous deletion of the SMN1 gene. ${ }^{[1]}$ The number of copies of SMN2 is responsible for the severity of the disease. ${ }^{[31]}$ Patients have at least one copy of 2-4 SMN2 copies.[31] Typically, SMA type 1 patients have two copies, type 2 patients have three, and type 3 and 4 have three or four copies. ${ }^{[22-44]}$ Consequentially, patients with less SMN2 gene copies have greater severity of disease. ${ }^{[45]}$

\section{Epidemiology}

The autosomal recessive form of the disease is the second most common disease in children after cystic fibrosis and its incidence varies between $1 / 6,000-1 / 10,000$, while incidence of carriers ranges between $1 / 40-1 / 60 . .^{[46,47]}$

\section{Classification of disease and clinical findings}

Although SMA is one of the most common diseases in children, it may also affect adults. The International SMA consortium classifies childhood SMAs into three different categories: ${ }^{[48]}$

a. SMA type 1 (Werdnig-Hoffman's Disease/ Acute Infantile SMA)

b. SMA type 2 (Subacute Form/Intermediate Form)

c. SMA type 3 (Kugelberg-Welander Disease) 
Spinal muscular atrophy type 4 is the adult form of the disease. ${ }^{[49]}$ These clinical forms can be summarized as: type 1 cannot sit, type 2 cannot walk, and type 3 cannot run. Difficulty walking is also observed in type 4. ${ }^{[49]}$

\section{SMA type 1 (Werdnig-Hoffman Disease)}

This form has the earliest onset and is the severest form. ${ }^{[31]}$ It can occur at birth or in the first six months as well as in the prenatal period, in which case the patient is classified as type $0 .{ }^{[50]}$ These patients cannot control their heads or sit independently and have clinical symptoms of hypotonia, respiratory failure, muscle weakness, and difficulty swallowing and nursing. ${ }^{[31,51]}$ Patients usually die before age two. ${ }^{[31]}$

\section{SMA type 2 (Subacute/Intermediate Form)}

Clinical symptoms emerge within the first 7-18 months of early life. ${ }^{[31]}$ Patients can sit unsupported but cannot walk by themselves. ${ }^{[1,31]}$ Clinical symptoms include tremor, joint contractures, and scoliosis. ${ }^{[31]}$ Most patients reach adulthood but usually suffer early morbidity and mortality due to respiratory failure. ${ }^{[1]}$

\section{SMA type 3 (Kugelberg-Welander)}

This form is the mildest form of the disease. ${ }^{[52]}$ Symptoms begin after 18 months, presenting as proximal muscle weakness. ${ }^{[1,31]}$ A portion of patients lose their ability to walk at some point of their life. ${ }^{[1]}$ Patients who lose their ability to walk develop conditions such as osteoporosis, obesity, and scoliosis. ${ }^{[31,53-55]}$

\section{SMA type 4 (Adult SMA)}

This form occurs in adults. Proximal muscle weakness is present. These patients can walk by themselves. ${ }^{[31]}$

\section{Diagnosis}

There is currently no cure for SMA. ${ }^{[31]}$ Symptomatic therapies can be applied to improve clinical symptoms. Physical therapy can prevent complications of muscle weakness and orthopedic treatment can improve scoliosis. When left untreated, difficulty in breathing may develop. Since mortalities due to respiratory failure are common especially in type 1 and type 2, respiratory treatment is considerably important in these patients. ${ }^{[56]}$ For medical treatment, nusinersen (Spinraza) is used. Although the SMN1 gene produces the functional SMNFL, SMNFL is produced only by SMN2 in a very low amount (10\%) because SMN1 gene is disrupted in the majority of patients. SMN2 mostly produces SMN $\Delta 7$ (90\%). These products are unstable and undergo degradation. Nusinersen effects the SMN2 gene by increasing the number of SMN2 copies and amount of functional protein. ${ }^{[57]}$

\section{Declaration of conflicting interests}

The authors declared no conflicts of interest with respect to the authorship and/or publication of this article.

\section{Funding}

The authors received no financial support for the research and/or authorship of this article.

\section{REFERENCES}

1. Tiryaki E, Horak HA. ALS and other motor neuron diseases. Continuum (Minneap Minn) 2014;20:1185207.

2. Rowland LP. Diverse forms of motor neuron diseases. Adv Neurol 1982;36:1-13.

3. Manjaly ZR, Scott KM, Abhinav K, Wijesekera L, Ganesalingam J, Goldstein LH, et al. The sex ratio in amyotrophic lateral sclerosis: A population based study. Amyotroph Lateral Scler 2010;11:439-42.

4. Testa D, Lovati R, Ferrarini M, Salmoiraghi F, Filippini G. Survival of 793 patients with amyotrophic lateral sclerosis diagnosed over a 28-year period. Amyotroph Lateral Scler Other Motor Neuron Disord 2004;5:208-12.

5. Cudkowicz ME, McKenna-Yasek D, Sapp PE, Chin W, Geller B, Hayden DL, et al. Epidemiology of mutations in superoxide dismutase in amyotrophic lateral sclerosis. Ann Neurol 1997;41:210-21.

6. Juneja T, Pericak-Vance MA, Laing NG, Dave S, Siddique T. Prognosis in familial amyotrophic lateral sclerosis: progression and survival in patients with glu100gly and ala4val mutations in $\mathrm{Cu}, \mathrm{Zn}$ superoxide dismutase. Neurology 1997;48:55-7.

7. Rosen DR, Siddique T, Patterson D, Figlewicz DA, Sapp P, Hentati A, et al. Mutations in $\mathrm{Cu}$ / $\mathrm{Zn}$ superoxide dismutase gene are associated with familial amyotrophic lateral sclerosis. Nature 1993;362:59-62.

8. Ticozzi N, Tiloca C, Morelli C, Colombrita C, Poletti B, Doretti A, et al. Genetics of familial Amyotrophic lateral sclerosis. Arch Ital Biol 2011;149:65-82.

9. Pasinelli P, Borchelt DR, Houseweart MK, Cleveland DW, Brown RH Jr. Caspase- 1 is activated in neural cells and tissue with amyotrophic lateral sclerosis-associated mutations in copper-zinc superoxide dismutase. Proc Natl Acad Sci U S A 1998;95:15763-8. 
10. Neumann M, Sampathu DM, Kwong LK, Truax AC, Micsenyi MC, Chou TT, et al. Ubiquitinated TDP-43 in frontotemporal lobar degeneration and amyotrophic lateral sclerosis. Science 2006;314:130-3.

11. Lahut S, Özeş B, Ağar S, Başak AN. TDP-43 Proteinopatileri: Nörodejeneratif Konformasyon Bozukluğu Hastalıklarında Yeni Bir Oyuncu. Turk J Neurol 2012;18:1-10.

12. Ratti A, Buratti E. Physiological functions and pathobiology of TDP-43 and FUS/TLS proteins. J Neurochem 2016;138:95-111.

13. Vance C, Rogelj B, Hortobágyi T, De Vos KJ, Nishimura AL, Sreedharan J, et al. Mutations in FUS, an RNA processing protein, cause familial amyotrophic lateral sclerosis type 6. Science 2009;323:1208-11.

14. Kwiatkowski TJ Jr, Bosco DA, Leclerc AL, Tamrazian $\mathrm{E}$, Vanderburg $\mathrm{CR}$, Russ $\mathrm{C}$, et al. Mutations in the FUS/TLS gene on chromosome 16 cause familial amyotrophic lateral sclerosis. Science 2009;323:1205-8.

15. Kiernan MC, Vucic S, Cheah BC, Turner MR, Eisen A, Hardiman O, et al. Amyotrophic lateral sclerosis. Lancet 2011;377:942-55.

16. Wokke JH. Confounding effects of mimicking disorders in the early diagnosis of amyotrophic lateral sclerosis. Amyotroph Lateral Scler Other Motor Neuron Disord 2000;1:S61-3.

17. Ross MA. Clinical features and diagnosis of amyotrophic lateral sclerosis. CONTINUUM: Lifelong Learning in Neurology 2002;8:9-31.

18. Li T M, Alberman E, Swash M. Comparison of sporadic and familial disease amongst 580 cases of motor neuron disease. J Neurol Neurosurg Psychiatry 1988;51:778-84.

19. Kurland LT, Mulder DW. Epidemiologic investigations of amyotrophic lateral sclerosis. Neurology 1955;5:182-96.

20. Rowland LP, Shneider NA. Amyotrophic lateral sclerosis. N Engl J Med 2001;344:1688-700.

21. Ravits JM, La Spada AR. ALS motor phenotype heterogeneity, focality, and spread: deconstructing motor neuron degeneration. Neurology 2009;73:805-11.

22. Picher-Martel V, Valdmanis PN, Gould PV, Julien JP, Dupré N. From animal models to human disease: a genetic approach for personalized medicine in ALS. Acta Neuropathol Commun 2016;4:70.

23. Swinnen $B$, Robberecht $W$. The phenotypic variability of amyotrophic lateral sclerosis. Nat Rev Neurol 2014;10:661-70.

24. Ferguson TA, Elman LB. Clinical presentation and diagnosis of amyotrophic lateral sclerosis. NeuroRehabilitation 2007;22:409-16.

25. Chiò A, Calvo A, Moglia C, Mazzini L, Mora G; PARALS study group. Phenotypic heterogeneity of amyotrophic lateral sclerosis: a population based study. J Neurol Neurosurg Psychiatry 2011;82:740-6.

26. Ringholz GM, Appel SH, Bradshaw M, Cooke NA,
Mosnik DM, Schulz PE. Prevalence and patterns of cognitive impairment in sporadic ALS. Neurology 2005;65:586-90.

27. Joyce NC, Carter GT. Electrodiagnosis in persons with amyotrophic lateral sclerosis. PM R 2013;5:S89-95.

28. Brooks BR, Miller RG, Swash M, Munsat TL; World Federation of Neurology Research Group on Motor Neuron Diseases. El Escorial revisited: revised criteria for the diagnosis of amyotrophic lateral sclerosis. Amyotroph Lateral Scler Other Motor Neuron Disord 2000;1:293-9.

29. de Carvalho M, Dengler R, Eisen A, England JD, Kaji R, Kimura J, et al. Electrodiagnostic criteria for diagnosis of ALS. Clin Neurophysiol 2008;119:497-503.

30. Costa J, Swash M, de Carvalho M. Awaji criteria for the diagnosis of amyotrophic lateral sclerosis:a systematic review. Arch Neurol 2012;69:1410-6.

31. D'Amico A, Mercuri E, Tiziano FD, Bertini E. Spinal muscular atrophy. Orphanet J Rare Dis 2011;6:71.

32. Burghes AH, Beattie CE. Spinal muscular atrophy: why do low levels of survival motor neuron protein make motor neurons sick? Nat Rev Neurosci 2009;10:597-609.

33. Lefebvre S, Bürglen L, Reboullet S, Clermont O, Burlet $\mathrm{P}$, Viollet $\mathrm{L}$, et al. Identification and characterization of a spinal muscular atrophy-determining gene. Cell 1995;80:155-65.

34. Vitte J, Fassier C, Tiziano FD, Dalard C, Soave $\mathrm{S}$, Roblot $\mathrm{N}$, et al. Refined characterization of the expression and stability of the SMN gene products. Am J Pathol 2007;171:1269-80.

35. Coovert DD, Le TT, McAndrew PE, Strasswimmer J, Crawford TO, Mendell JR, et al. The survival motor neuron protein in spinal muscular atrophy. Hum Mol Genet 1997;6:1205-14.

36. Lorson CL, Hahnen E, Androphy EJ, Wirth B. A single nucleotide in the SMN gene regulates splicing and is responsible for spinal muscular atrophy. Proc Natl Acad Sci U S A 1999;96:6307-11.

37. Chi-Ming Wong, Lu Xu, Mabel Yin-Chun Yau. Alternative mRNA Splicing in the Pathogenesis of Obesity. Int J Mol Sci 2018;19:632.

38. Burnett BG, Muñoz E, Tandon A, Kwon DY, Sumner CJ, Fischbeck KH. Regulation of SMN protein stability. Mol Cell Biol 2009;29:1107-15.

39. Lorson CL, Strasswimmer J, Yao JM, Baleja JD, Hahnen E, Wirth B, et al. SMN oligomerization defect correlates with spinal muscular atrophy severity. Nat Genet. 1998;19:63-6.

40. Pellizzoni L, Charroux B, Dreyfuss G. SMN mutants of spinal muscular atrophy patients are defective in binding to snRNP proteins. Proc Natl Acad Sci U S A 1999;96:11167-72.

41. Wirth B. An update of the mutation spectrum of the survival motor neuron gene (SMN1) in autosomal recessive spinal muscular atrophy (SMA). Hum Mutat 2000;15:228-37. 
42. Gavrilov DK, Shi X, Das K, Gilliam TC, Wang $\mathrm{CH}$. Differential SMN2 expression associated with SMA severity. Nat Genet 1998;20:230-1.

43. Feldkötter M, Schwarzer V, Wirth R, Wienker TF, Wirth B. Quantitative analyses of SMN1 and SMN2 based on real-time lightCycler PCR: fast and highly reliable carrier testing and prediction of severity of spinal muscular atrophy. Am J Hum Genet 2002;70:358-68.

44. Rudnik-Schöneborn S, Berg C, Zerres K, Betzler C, Grimm T, Eggermann T, et al. Genotype-phenotype studies in infantile spinal muscular atrophy (SMA) type I in Germany: implications for clinical trials and genetic counselling. Clin Genet 2009;76:168-78.

45. Cartegni L, Krainer AR. Disruption of an SF2/ASFdependent exonic splicing enhancer in SMN2 causes spinal muscular atrophy in the absence of SMN1. Nat Genet 2002;30:377-84.

46. Ogino S, Leonard DG, Rennert H, Ewens WJ, Wilson RB. Genetic risk assessment in carrier testing for spinal muscular atrophy. Am J Med Genet 2002;110:301-7.

47. Prior TW, Snyder PJ, Rink BD, Pearl DK, Pyatt RE, Mihal DC, et al. Newborn and carrier screening for spinal muscular atrophy. Am J Med Genet A 2010;152:1608-16.

48. Munsat TL, Davies KE. International SMA consortium meeting. (26-28 June 1992, Bonn, Germany). Neuromuscul Disord 1992;2:423-8.

49. Wirth B, Brichta L, Schrank B, Lochmüller $H$, Blick S, Baasner A, et al. Mildly affected patients with spinal muscular atrophy are partially protected by an increased SMN2 copy number. Hum Genet 2006;119:422-8.

50. MacLeod MJ, Taylor JE, Lunt PW, Mathew CG, Robb SA. Prenatal onset spinal muscular atrophy. Eur J Paediatr Neurol 1999;3:65-72.

51. Ogino S, Wilson RB. Genetic testing and risk assessment for spinal muscular atrophy (SMA). Hum Genet 2002;111:477-500.

52. Kim CA, Passos-Bueno MR, Marie SK, Cerqueira A, Conti U, Marques-Dias MJ, et al. Clinical and molecular analysis of spinal muscular atrophy in Brazilian patients. Genet Mol Biol 1999;22:487-92.

53. Kinali M, Banks LM, Mercuri E, Manzur AY, Muntoni F. Bone mineral density in a paediatric spinal muscular atrophy population. Neuropediatrics 2004;35:325-8.

54. Khatri IA, Chaudhry US, Seikaly MG, Browne $\mathrm{RH}$, Iannaccone ST. Low bone mineral density in spinal muscular atrophy. J Clin Neuromuscul Dis 2008;10:11-7.

55. Shanmugarajan S, Tsuruga E, Swoboda KJ, Maria BL, Ries WL, Reddy SV. Bone loss in survival motor neuron (Smn(-/-) SMN2) genetic mouse model of spinal muscular atrophy. J Pathol 2009;219:52-60.

56. Wang $\mathrm{CH}$, Finkel RS, Bertini ES, Schroth M, Simonds A, Wong B, et al. Consensus statement for standard of care in spinal muscular atrophy. J Child Neurol 2007;22:1027-49.

57. Bowerman M, Becker CG, Yáñez-Muñoz RJ, Ning $\mathrm{K}$, Wood MJA, Gillingwater $\mathrm{TH}$, et al. Therapeutic strategies for spinal muscular atrophy: SMN and beyond. Dis Model Mech 2017;10:943-54. 